\title{
THE STEADY STATE THEORY: RECALIBRATING THE QUIDDITY OF AMBIENT MUSIC
}

\section{Simon Cummings}

“Plus ça change, plus c'est la même chose.”- Jean-Baptiste Alphonse Karr ${ }^{1}$

\section{Introduction}

As the superstitions of religious interpretation have given way to the rational rigour of scientific investigation, so our understanding of the nature of the universe has fundamentally shifted. Symbolism, significance, order and limitation have been replaced by meaninglessness, insignificance, randomness and infinity. As we look up at the stars, gazing out and beyond what we think of as home, our perception passes ever further away from the specific to the generalised, an existence characterised by a uniform distribution of elements (bomogeneity) appearing the same from all vantage points and in all directions (isotropy). ${ }^{2}$ From this universal perspective everything may be precious, but nothing is privileged.

In tandem with our understanding of how things are, how they came to be has been similarly scrutinised. The twentieth century brought numerous theories regarding such origins (or lack of them), proposing either that the universe had no fixed beginning - Fred Hoyle's 'steady state' model - or that it all began instantaneously in an enormous conflagration, the well-known 'big

\footnotetext{
1 Les Gueppes January 1849 (6th series, 1859), in Oxford Essential Quotations, Sixth Edition, ed. Susan Ratcliffe (Oxford University Press, 2018).

2 These twin elements are what constitutes the cosmological principle, originally asserted by Isaac Newton.
} 
bang' theory. ${ }^{3}$ The latter has become firmly established as the most compatible with contemporary cosmological understanding, though arguments remain and further theories (including attempts to combine the steady state and big bang models $)^{4}$ continue to be proposed. ${ }^{5}$

It is perhaps not too fanciful a parallel to say that musical compositions can be regarded as sonic universes. They contain objects arranged and positioned in a particular way, distributed with varying densities, according to the most strict or arbitrary organisational rules and schemes. They surround and envelop us, our role as listeners becoming akin to travellers drifting and exploring their inner worlds. Within and around these worlds we are able to perceive everything from the gigantic to the infinitesimal, events that happen in the blink of an eye or which play out over extended periods of time. And while music is inevitably limited by being temporal, bound to and by time, it can in both its objective behaviour and subjective character suggest and evoke the infinite.

Just as our understanding and interpretation of the universe is by necessity subject to continual scrutiny, challenge and revision, the same is true of music, and particularly true, arguably belatedly so, of ambient music. In the four decades since Brian Eno first coined the term 'ambient' to describe a particular kind of musical outlook and practice, what that term connotes has become increasingly simplified, assumption-laden and formulaic. Greek musician Vangelis has complained that it "gave the opportunity for untalented people

3 For an introduction to the steady state model see F. Hoyle, "A new model for the expanding universe," Monthly Notices of the Royal Astronomical Society 108(5) (1948) and H. Bondi, T. Gold, "The Steady-State Theory of the Expanding Universe," Monthly Notices of the Royal Astronomical Society 108(3) (1948). A commentary on the origins of the big bang theory can be found in Jean-Pierre Luminet, "Editorial note to: George Lemaître, The beginning of the world from the point of view of quantum theory," General Relativity and Gravitation, 43(10) (2011): 2911-2928.

4 The so-called 'steady bang' model; see F. Hoyle, G. Burbidge, J. V. Narlikar, "A Quasi-Steady State Cosmological Model with Creation of Matter," The Astrophysical Journal 410 (1993): 437-457.

5 For an excellent overview of the history and arguments, see Helge Kragh, "Cosmology and the origin of the universe: Historical and conceptual perspectives," arXiv preprint arXiv:1706.00726 (2017). 
to make very boring music", ${ }^{6}$ and indeed, a cursory survey of contemporary examples of music described by its creators as 'ambient' might lead one to conclude that its conception rests upon and revolves around little more than the conjunction of a few very basic, superficial characteristics, which might be summarised as: slow, quiet, relaxing and beautiful.

Admittedly, it is true that several of these epithets could be said to apply to the first album to use the term 'ambient', Brian Eno's 1978 Ambient 1: Music for Airports. The album's four movements are very obviously designed to be quietly subdued, a deliberate effort on Eno's part - elaborated in the album's liner notes - to enable the music to "accommodate many levels of listening attention without enforcing one in particular", thereby affording the listener the potential for a uniquely polarised form of engagement, able to regard the music as, by turns, "ignorable" and "interesting". ${ }^{7}$ Furthermore, each movement of Music for Airports is constructed from a small number of brief, repeating melodic gestures which overlap each other with unpredictable freedom while remaining harmonically fixed, strictly diatonic with regard to an unchanging underlying tonality. It would be easy to assume that the dominant traits of Music for Airports - and, therefore, the definition of ambient music itself - emerge from this particular combination of gentle, sedate consonance.

In this chapter I will argue that this assumption is a fallacy, at odds with both the non-specific openness of Eno's own definition of ambient - encapsulated in his 'ignorable'/'interesting' dichotomy - as well as the fundamental musical paradigm that he established in Music for Airports in order to directly manifest that dichotomy. In an attempt to recalibrate the history, definition and outlook of ambient music, I will argue that, from the perspectives of both composer and listener, it is this same paradigm that

6 Peter Culshaw, "My Greek odyssey with Alexander," The Guardian, January 6, 2005, https://www. telegraph.co.uk/culture/music/3634447/My-Greek-odyssey-with-Alexander.html.

7 Brian Eno, "Ambient Music", liner notes from Ambient 1: Music for Airports (PVC 7908 (AMB 001), 1978), accessed March 20, 2019, http://music.hyperreal.org/artists/brian_eno/MFA-txt.html. 
constitutes the defining aspect of ambient qua ambient: a generalised modus operandi that I call a steady state.

The steady state: definition and antecedents

Hoyle's 'steady state' cosmological model posited a situation in which there was neither a beginning and end to the universe nor any significant overall difference in its nature and composition. As such, the universe existed in a state of equilibrium, in which change occurred on smaller scales of distance, density and time but over larger scales was essentially changeless and static. Another way of putting this is to say that the concept of a steady state indicates not a stasis of detail but of behaviour; the generalised 'rules' governing the steady state are essentially encoded into an underlying behavioural definition which never alters, yet that definition nonetheless specifies (or, at least, allows) creation, variation and change.

It is not difficult to conceive of a musical equivalent of the steady state model. Indeed, Brian Eno's dichotomy potentially offers just such an equivalence, suggesting a musical environment containing 'ignorable' elements that over the long-term remain static and thereby discourage active listening, and 'interesting' elements that undergo short-term change, inviting listener engagement. As I will show, Eno's Music for Airports is an example of precisely this kind of musical steady state in action. Yet while Eno's development of this idea was innovative and new, it owed a debt to numerous antecedents and prototypes of demonstrably similar musical environments and processes.

Discussion about 'proto-ambient' tends without exception to reach to the music of Erik Satie as a precursor. Though very often cited, ${ }^{8}$ from the perspective of steady states, Satie's piano work Vexations (c. 1893) is an

8 cf. Mark Prendergast, The Ambient Century (London: Bloomsbury, 2003), 6; Paul Morley, Op. cit., 33; Alan Licht, "Sound Art: Origins, development and ambiguities," Organised Sound, 14(1) (2009), 3-10; Eliot Bates, "Ambient Music" (Masters diss., Wesleyan University, 1997), 152. There are innumerable such examples in the literature; indeed, it would probably be easier to cite cases that do not mention Satie than those that do. 
irrelevant point of reference. This may seem a strange assertion since the piece is so directly concerned with maintaining an unchanging state - the same passage of music performed 840 times - over a consequently extended duration. The key difference, however, is in this very exactitude. A musical steady state requires unpredictability, or at least variability, of its parameters at smaller-scale durations, whereas Vexations employs exact repetition and thereby creates music that does not exhibit short-term material change. ${ }^{9}$ As such, Vexations is a piece solely concerned with long-term behaviour that, in ambient parlance, we would characterise as being wholly 'ignorable' (which, considering the work's title, is hardly surprising).

For the same reason, Satie's musique d'ameublement ('furnishing' or, more commonly, 'furniture' music) is of minimal relevance with regard to steady states. A collection of five short pieces composed between 1917 and 1923, described by Dylan Trigg as "a type of music that must not individuate itself, must not display any excessive idiosyncrasy, but rather blend seamlessly into the background, surreptitiously enforcing an environment that the listener is unaware of ${ }^{10}{ }^{10}$ the concept obviously invites immediate comparisons with ambient. However, these pieces similarly rely upon strict repetition of very short musical phrases, and so are focused again, entirely deliberately, on the creation of 'ignorable' music. Indeed, Satie himself was vehemently adamant that these pieces should in no way be actively listened to, urging the audience, "to take no notice of it and to behave ... as if it did not exist. This music ... claims to make a contribution to life in the same way as ... a painting in a gallery, or the chair on which you may or may not be seated". ${ }^{11}$ It is interesting to note that, despite Satie's adjurations, and the forbidding reality of music

9 I do not consider accidental considerations such as minor performance variations caused by performer fatigue or the occasional presence of mistakes as meaningful instances of 'change' in this context.

10 Dylan Trigg, "Furniture music, hotel lobbies, and banality: Can we speak of a disinterested space?," Space and Culture, 9(4) (2006): 7.

11 Nicola Bernardini, "Erik Satie's Musique d'Ameublement, some ninety years later," in Furniture Music (Venice: Blauerhase), 22. 
with "no variations, no extensions, ... no evolution" that is consequently "exasperatingly static, and ... does not seek to offer any solution nor escape to its staticity", ${ }^{12}$ the audience nonetheless listened with rapt attention, to Satie's considerable annoyance.

These works by Satie point more directly towards minimalism, early examples of which include nascent precursors of steady states. Terry Riley's In $C$ (1964) uses a process by which 53 individually-numbered bars are repeated an arbitrary number of times by each of the unspecified number of players. Though the work has a notionally linear direction, each player methodically working their way through the sequence of bars, this is undermined and diminished by the nature of Riley's musical material. The bars themselves - in terms of their actual content, plus the fact that they are subject to continuous rapid repetition - are from a listening perspective all relatively innocuous, so attention is theoretically only drawn to them when they first occur in a particular part. Furthermore, depending on the number of players, which could be considerable, ${ }^{13}$ not all such occurrences will even be audible. The combined effect of these multiple bars sounding simultaneously thus creates washes of generalised sound that, in the short term, include occasional periods of interest due to individual points of change, while over the long term they present an essentially static environment with only modest shifts in harmonic emphasis, never significantly deviating from the purview of its underlying $\mathrm{C}$-based tonality. This corresponds closely to the small-scale 'interesting' detail and large-scale 'ignorable' stasis of the steady state.

Steve Reich's 'phase' works from the late 1960s illustrate something similar. In Piano Phase (1967) the first of the two pianists performs an unchanging 12 -semiquaver pattern for the entire duration of the work. The second pianist, performing the same pattern, alternates between sections where their rhythms are aligned with the first pianist (the two players beginning

12 Ibid., 23.

13 In the preface to the score, Riley states the most desirable number of players to be approximately 35 . 
synchronised with each other) and episodes where they slowly accelerate until their material falls back into rhythmic alignment, now one extra semiquaver ahead of the first pianist. The piece thereby establishes episodes of stasis when the two players are rhythmically aligned, and temporary periods of transitional change during which rhythmic synchronicity is lost, over the long term creating something similar to a steady state.

Not all precursors of steady states are as highly energetic or rhythmicallydriven as these examples by Riley and Reich. Tony Scott's Music for Zen Meditation (1964), an early example of New Age music, features a collection of trios combining Scott's clarinet with koto and shakuhachi. These pieces comprise slow streams of improvised melody and counterpoint, the three players intermingling their ideas in an attitude of quiet solemnity. As a consequence, none of the nine tracks is meaningfully different from any of the others, and the album as a whole acts not unlike a steady state, articulating an unchanging behaviour of quiet, randomised, diatonic counterpoint. Likewise, jazz flautist Paul Horn's 1968 album Inside features a collection of improvisations recorded in the Taj Mahal, exploring and interacting with the effect of its vast reverberant space. Horn's approach in each piece is essentially the same, the music consisting of short tendrils and gestures (combining both flute and the chanting of a male sentry) interspersed with pauses during which the reverberation, literally, fills the space. This amounts to a behavioural stasis in which individual phrases, and the compositions they nominally create, are all unique in the short term yet overall have no substantive distinction from each other.

It should be noted that in both these cases the music was created to serve a distinct functional end, to act as a suitable medium for the listener to engage in states of meditation. ${ }^{14}$ As such, they are in both intention and execution not merely similar but equivalent, with only superficial musical differences:

14 The simple title of Paul Horn's Inside can be read as a double meaning, beyond its immediate reference to the Taj Mahal, hinting at a connection to an inner world of contemplation. 
Scott meditating on Japanese Buddhist ideas in an intimate space, Horn on Indian Hinduist concepts within a reverberant public space, both articulated via the use of steady states. The capacity of the steady state to function in this way will be explored in more depth later.

Around the same time, the evolution of steady states was aided to a large extent by developments in psychedelic and progressive rock. In particular, several of Pink Floyd's albums from the late 1960s and early 1970s feature examples of quasi-steady states. "Careful With The Axe, Eugene" "Set the Controls for the Heart of the Sun" (Ummagumma, 1969), "Echoes" (Meddle, 1971), "On The Run"(Dark Side of the Moon, 1973) and "Shine On You Crazy Diamond" (Wish You Were Here, 1975) all include extended sequences where meandering surface details are placed over behavioural and/or harmonic stases. Though in most cases they ultimately form part of bigger, directionally linear structures - often acting as introductions to or periods of reflection between recognisable verse sections - it is clear that Pink Floyd were seeking to move far beyond the boundaries of conventional song forms and take the listener on larger-scale sonic journeys with much broader scope.

The most compelling instances of quasi-steady states in music from this time can be found in the offshoot of prog rock that came to be known as kosmische musik. The term was coined by German musician Edgar Froese, whose group Tangerine Dream, one of the first to harness emerging analogue synthesiser technology, took inspiration from the burgeoning interest in space exploration that came in the wake of the moon landings in 1969. Although their early work is clearly indebted in both style and structure to the Pink Floyd examples referred to above (as well as that group's earlier psychedelic period), Tangerine Dream was not a conventional rock group setting out to compose songs. On the contrary, Alexander Harden has commented on the use of electronics and avoidance of the human voice (in tandem with a much-reduced emphasis on the significance of performers) being means to distance kosmische musik from the aesthetic conventions of popular music at that time, employing sounds "that do not appear to originate from acoustical sources, which further contributes to 
the music's surreal or otherworldly character". ${ }^{15}$ This freed Tangerine Dream to explore more undefined, non-linear musical structures.

In their 1971 album Alpha Centauri, slow-moving environments are established that are either rooted in rotating sequences of chords ("Fly and Collision of Comas Sola") or shimmering collections of drones ("Alpha Centauri"). These two ideas would gradually coalesce on Tangerine Dream's subsequent releases, in the process developing a more patient approach to structure, allowing the rate at which their environments changed to slow considerably. "Origin of Supernatural Probabilities", on the album Zeit (1972), is a striking early example of this, progressing from a gentle, dreamy opening into muffled pulsations. These pulsations evoke things organic (akin to a heart pumping) and machine-like, above which arbitrary elements chord clusters, quiet stings, wind-like sounds - appear and overlap. Not only is this behavioural paradigm allowed to persist for a long time (lasting around nine minutes), but it is noticeably restrained, almost appearing to be taking place somewhere in the middle distance rather than seeking to make a conventionally strong foreground impact.

This ostensible indifference, or at least increased passivity, with regard to traditional notions of musical development and structure, as well as audience engagement, creates music that, invoking Eno's dichotomy, could well be described as 'ignoresting'. Atem (1973) and Phaedra (1974) continued to explore this approach, with the two albums sharing a four-part structure that progresses from long to short durations. It is therefore primarily in their respective opening tracks, being the longest, that these states are most clearly heard. The title track of Phaedra, in particular, which functions clearly as a steady state, established an archetype that would form the basis for much of Tangerine Dream's music until the end of the 1970s. The stasis is articulated via rapid, repeating arpeggiations, usually located in the bass; the pitch content of these

15 Alexander C. Harden, "Kosmische Musik and Its Techno-Social Context," Journal of the International Association for the Study of Popular Music Vol. 6, No. 2 (2016): 161-2. 
arpeggiations varies from time to time but their tempo and character do not. Change is heard in a plethora of transitory ideas that play out on top of this: percussive gestures, potentially ominous chords, the makings of a melody, or just a simple octave doubling of the bass. The fast cycling arpeggiations give the impression of moving at considerable speed, making them the constant element which any and all other ideas seem to be almost literally rushing past. ${ }^{16}$

By this means, a steady state is created in which these rapid bass arpeggios combine the qualities of a bassline, a ground bass and a texture, becoming an unchanging, underpinning element over which pretty much anything else can happen, however seemingly disconnected, unexpected or ephemeral, and the music still hangs together and sounds unified. They thereby enable, in a more complex but similar way to that of Tony Scott and Paul Horn, meditative, non-developmental, improvisational forms of musical structure. This became the basis for Tangerine Dream's subsequent albums Rubycon (1975) and Stratosfear (1976), their respective steady states again constructed on a bedrock of drones and/or ostinato arpeggios upon which transient elements unpredictably emerge and recede. These states, especially on Rubycon, are sometimes used to create subsections in larger composite structures, a practice not dissimilar to the early albums of French musician Jean-Michel Jarre, Oxygene (1976) and Equinoxe (1977). With their respective poles of long-term stasis and short-term change, resulting in different forms of 'ignoresting' music, it is not difficult to regard any of these works, at least in part, as being ambient in nature.

\section{Brian Eno and the conception of ambient}

Brian Eno's conception and earliest exploration of this balance between interest and ignorability date from this same period in the mid-1970s. Eno's

16 Though aspiring to a very different musical aesthetic, and inspired more by things terrestrial than cosmic, an identical approach can be heard on Kraftwerk's 1974 track 'Autobahn', where varying combinations of repetitive beats and basslines form the firmament (or, in this case, 'highway') over which transient ideas pass by. Their 1977 track 'Trans-Europe Express' is arguably an even more austere version of this same idea. 
move away from the conventions of rock music (he was a founder member of UK glam rock band Roxy Music) had begun to take shape in his 1975 album Another Green World. Though the album's title does not necessarily connote the kind of interplanetary imaginings of Tangerine Dream, it can nonetheless be read as an allusion to another, perhaps parallel, 'earthly' reality with different conventions, hinting at an alternate kind of creativity. ${ }^{17}$ To that end, Eno experimented with introducing chance into the creative process, as well as using the 'Oblique Strategies' set of cards he had co-created with artist Peter Schmidt, which provide pithy prompts to aid and/or (re-)direct creative thinking. While Another Green World exhibits many traits derived from rock, several of its tracks utilise a similar kind of steady state to that of Tangerine Dream. "In Dark Trees" features the combination of a percussion-heavy rhythmic underlay and a cycling four-chord progression as an unchanging foundation for extemporised ideas above, while the title track more gently oscillates between just two chords. Elsewhere, Eno explored even more freewheeling and meandering ideas: 'Becalmed' lives up to its name, its eight chords, emerging from soft wind, slowly and dreamily repeating with only minor adjustments to timbre and embellishment; while 'Little Fishes' sleepily toys with a wobbling melody in an unchanging, dizzy environment infused with lullaby.

Eno developed these latter ideas into the first iteration of the 'ignoresting' dichotomy on his next album, Discreet Music (1975). The catalyst for this development - so often recounted as to have become by now almost legendary - was as much imposed as inspired, arising from the aftermath of an accident that resulted in Eno being uncomfortably confined to his bed. He recounts:

My friend Judy Nylon visited me and brought me a record of 18th century harp music. After she had gone, and with some considerable difficulty, I put on the record. Having laid down, I realized that the

17 Considering where Eno's ambient musical explorations would subsequently lead, the title's implications of landscape are also noteworthy. 
amplifier was set at an extremely low level, and that one channel of the stereo had failed completely. Since I hadn't the energy to get up and improve matters, the record played on almost inaudibly. This presented what was for me a new way of hearing music - as part of the ambience of the environment just as the colour of the light and the sound of the rain were parts of that ambience. It is for this reason that I suggest listening to the piece at comparatively low levels, even to the extent that it frequently falls below the threshold of audibility. ${ }^{18}$

This in turn led him, in the title track of Discreet Music, to seek to replicate something of this peculiarly passive mode of engagement. To that end, passivity was made a fundamental part of the composition process itself, Eno setting up loops of music on a long delay system that, once set running, were not otherwise interfered with apart from "providing ... two simply and mutually compatible melodic lines" and "occasionally altering the timbre of the synthesiser's output". ${ }^{19}$ This latter involvement plays a similar role to the use of synthesisers in Tangerine Dream's kosmische musik; while the nature of Eno's looped materials often evokes or resembles acoustic instruments (particularly woodwind), they remain sufficiently anonymous that any putative identity or connection to real acoustic sounds - or even synthesised sounds, for that matter - is rendered moot.

The music's abiding gentleness - almost defiantly unemphatic, remaining in the middle distance - is an important factor in the soundworld of "Discreet Music", as is its particular use of harmony. Eric Tamm has noted how Eno's use of a $\mathrm{G}$ major triad in second inversion, avoiding the root of the chord, aids the long-term continuation of the piece. ${ }^{20}$ The effect is like a cadence

18 Brian Eno, liner notes from Discreet Music (obscure no. 3, 1975).

19 Ibid.

20 Eric Tamm, Brian Eno: His Music and the Vertical Colour of Sound (Boston: Da Capo Press, 1995), 131. 
on the cusp of resolution, caught at a liminal point between movement and rest. Most significant of all though is the work's fundamental behaviour, its process of overlapping, non-synchronised loops. It is this above all else that establishes the music's heightened, timeless, meditative effect, perpetually changing while remaining eternally the same. As such, its 311/2-minute duration is an entirely arbitrary decision, providing a window onto a musical landscape that ultimately could, and perhaps should, play on forever. In the same way that Steve Reich spoke of a "compositional process and a sounding music that are one and the same thing", ${ }^{1}$ "Discreet Music" is both a proof-ofconcept and fully-functioning prototype of a steady state as the sole basis for composition. Furthermore, it is the first unequivocal example in Brian Eno's output of what he and everybody else would soon call ambient music.

A melding of the worlds of kosmische musik and proto-ambient came in 1977 with a collaboration between Eno and German group Cluster. A duo comprising Hans-Joachim Roedelius and Dieter Moebius, Cluster's work through the early 1970s had borne a conceptual and technological similarity to Tangerine Dream, embracing new synthesiser technology to create extensive, improvisational soundscapes. Aesthetically, Cluster's earliest music (as heard on their first two albums, Cluster (1971) and Cluster II (1972)) contrasted sharply with that of Tangerine Dream, directly harnessing drones and noise, the latter to an extent anticipating industrial music. But from the mid-1970s, the duo sought to explore a much gentler amalgam of free-form structures and embryonic electronic pop (using early drum machines, bearing a strong resemblance to Kraftwerk's Ralf and Florian (1973)). Much of their 1974 album Zuckerzeit, in a smaller-scale but nonetheless extremely similar way to Tangerine Dream, consists of rhythmic patterns and undulating arpeggiations (with unchanging harmony) acting as an underlay for melodic improvisations. Their next album, Sowiesoso (1976), was gentler still and draws marked similarities to the non-vocal tracks of Eno's Another Green

21 Steve Reich, Writings on Music, 1965-2000 (Oxford University Press, 2004), 35. 
World, its seven tracks either drone-based or built upon languid cycling chord progressions.

Eno had encountered Roedelius and Moebius earlier in the 1970s through the Krautrock group Harmonia, a collaboration with Neu!'s Michael Rother. Eno's appreciation for the group, and particularly for Cluster's album Zuckerzeit, was evidently considerable; David Sheppard recounts Eno spontaneously getting involved at a Harmonia concert in 1974:

\begin{abstract}
During the latter half of the gig Eno clambered on stage in an act of uncharacteristic showmanship and joined in on synthesizer. There was obvious delight from both sides - the mutual joy of discovering fellow travellers. Eno, as Roedelius recalls, wasn't there just to showboat: 'Brian did more than "jam" with us, it wasn't at the encore or anything, it was the whole second part of that concert - we just played some of our tracks and Brian was happy just to play along. ${ }^{22}$
\end{abstract}

This mutual appreciation found expression in the 1977 collaboration album Cluster E Eno, which in its soundworld is a clear fusion of Eno's "Discreet Music" and Cluster's Zuckerzeit and Sowiesoso. All of its nine tracks utilise steady states, eight of them founded upon harmonically fixed hovering drones or gently rhythmic ostinatos, over which free melodic ideas meander, with final track 'Für Luise' consisting of a barely-changing repeating progression of eight chords.

The consolidation and proliferation of steady states

In the liner notes to Discreet Music, Eno described the listening experience while recuperating from his accident as one where the music became "part of the ambience of the environment". He now made that idea the basis - and the prefix - for his new album, Ambient 1: Music for Airports. Eno's intentions were

22 David Sheppard, On Some Faraway Beach: The Life and Times of Brian Eno (Chicago Review Press, 2009), 185. 
principally functional, to create an "ambience ... defined as an atmosphere, or a surrounding influence: a tint" - yet not only, as its title implies, to be suitable when played within the unique environment of airports, but also, on a more personal level, "to induce calm and a space to think". ${ }^{23}$ To this end, like the meditation-inspired albums of Tony Scott and Paul Horn, Eno also utilised steady states as the means to create the album's four compositions, returning to the more emphatically hands-off, quasi-passive compositional approach used to compose "Discreet Music"(and which had not been used on Cluster E Eno).

Each of the four movements on Music for Airports utilises brief, simple melodic gestures that are looped to create a series of individual elements or strands heard simultaneously. As with "Discreet Music", the length of the gestures and the loops is such that synchronisation is completely coincidental. As such, the elements operate in a manner not dissimilar to the mediaeval practice of isorhythm, in which rhythmic and melodic components (the talea and color respectively), having different durations, are continually repeated, their asynchronous nature leading to musical patterns that are continually new yet which arise from a fixed and limited range of possibilities. If the relative durations are incommensurate with each other - which is to say their relative durations do not share common factors - these looping elements, once begun, will never again synchronise (or only after an extremely long period of time), resulting in music that never repeats and is literally always new. This was the method taken by Eno, who described the track " $2 / 1$ ” as being,

[...] structurally very, very simple. There are sung notes, sung by three women and myself. One of the notes repeats every $23^{1} \frac{1}{2}$ seconds. [...] The next lowest loop repeats every $25 \% / 8$ seconds or something like that. The third one every $29^{15} / 16$ seconds or something. What I mean is they all repeat in cycles that are called incommensurable

23 Brian Eno, "Ambient Music", liner notes from Ambient 1: Music for Airports (PVC 7908 (AMB 001), 1978), accessed March 20, 2019, http://music.hyperreal.org/artists/brian_eno/MFA-txt.html. 
- they are not likely to come back into sync again. [...] So as the piece progresses, what you hear are the various clusterings and configurations of these [...] basic elements. The basic elements in that particular piece never change. [...] But the piece does appear to have quite a lot of variety. [...] The thing about pieces like this of course is that they are actually of almost infinite length if the numbers involved are complex enough. They simply don't ever reconfigure in the same way again. ${ }^{24}$

Although Eno uses the word "repeat" several times in this description, and the behavioural definition of each movement's steady state is predicated on several elements repeating in this way, the resultant music does not overtly convey repetition at all. Rather, we are conscious of music with a generally isotropic nature - where new ideas closely resemble earlier ones, though we never perceive them to be exactly the same - and which, taken as a whole, clearly displays a well-defined, limited scope of activity. This is partly a consequence of the incommensurate nature of the elements' relative durations, but is also due to their rhythmic content being devoid of any underlying pulse or metric scheme, thereby militating against the notion of being connected at a fundamental level.

The strongest sense of connection comes from the elements' melodic aspect where, in the same way as in "Discreet Music" and throughout Cluster E Eno, each movement's pitch content is diatonic in relation to a fixed underlying tonality. In " $1 / 1$ " the effect is highly dronal, its combination of piano, electric piano and synthesiser never meaningfully deviating from the sense of a persistent D major triad. " $2 / 1$ " and " $1 / 2$ " - the latter track essentially a continuation of the former - are closer akin to Eno's (and Cluster's) previous use of chord progressions, conveying a sense of moving between chords I, IV

24 Brian Eno, “Generative Music," In Motion Magazine, accessed 27 April, 2019, http://www. inmotionmagazine.com/eno1.html. 
and VI of $A^{\mathrm{b}}$ major. ${ }^{25}$ The final track, " $2 / 2$ ", takes a slightly different approach, giving the impression of being anchored to a loose ground bass. In its clearest form, this ground would consist of the progression I - III - IV - V in the key of A major, though this is articulated more by implication than by example, and the piece instead presents a nebulous, never-ending oscillation between tension arising from this sense of chordal movement and quasi-cadential rest.

The way in which these fixed underlying harmonies are extended over time can be regarded as a form of Schenkerian prolongation, functioning, as music theorist Felix Salzer has described, "as the primordial prolongation of the tonality-indicating fundamental chord". Salzer regarded such prolongation as the "ultimate definition of tonality. [...] It is correct to say: Tonality is synonymous with chord prolongation". ${ }^{26}$ Though the tonal centres in Music for Airports are, in some cases, ambiguous - reinforced by Eno's general avoidance of positioning such a 'tonic' in an unequivocal root position - the harmonic limits are not. The diatonic nature of the meandering melody elements in each of the four movements acts to clarify and prolong these limits, over time clearly defining the harmonic palette of each piece.

However, within a steady state the concept of prolongation is extended beyond its function applying solely to harmony. As has already been described, the 'rules' encoded within the behavioural definition of a steady state are fixed and generalised, while allowing for specificity and change at a more superficial, short-term level. As a consequence, over longer-term durations - or across a sequence of separate but behaviourally analogous tracks - a steady state acts to clarify and prolong this limited, underlying range of behavioural activity. This kind of macro-structural meta-prolongation thus mirrors our understanding of the universe: specific details are non-teleological, only significant (if at all)

25 I disagree here with Eric Tamm, who claims the tonality to be rooted in a " $\mathrm{D}^{\mathrm{b}}$ major seventh chord with an added ninth" with "competing 'tonics' of $\mathrm{D}^{\mathrm{b}}$ and $\mathrm{A}^{\mathrm{b}}$ " (Op. cit., 133.). To my ear the pitches comprise a type of modified pentatonic scale on $\mathrm{Ab}\left(\mathrm{A}^{\mathrm{b}}-\mathrm{C}-\mathrm{D}^{\mathrm{b}}-\mathrm{E}^{\mathrm{b}}-\mathrm{F}\right)$ with the music oscillating between competing 'tonics' of $\mathrm{Ab}$ major and $\mathrm{F}$ minor.

26 Felix Salzer, Stuctural Hearing: Tonal coherence in music, Vol. 1 (Courier Corporation, 1962), 232.

Salzer's italics. 
at smaller-scale, local levels, in contrast to the homogeneous and isotropic nature of musical elements and actions over more extensive time periods. Crucially, therefore, steady states depend upon longer durations in order to be fully appreciated and effective, as I have previously observed:

This latter aspect, extended time, is vital: both as a compositional approach and a listening experience, [steady states] could be described as 'macrospective'; what happens moment by moment is of secondary importance to its long-term structural dimension. However, what makes 'steady statism' - to coin a phrase - so engaging is the way we as listeners are pulled back and forth between focusing on the short- and long-term actions of the music, ever aware of its essential open-endedness yet nonetheless engaged by the shifting, possibly transient, ways it is manifested on the surface. ${ }^{27}$

In many important respects, Eno's Music for Airports broke new ground. It introduced a new term, 'ambient', to the musical lexicon, together with a definition of that term, and provided an exemplar of its modus operandi, formalising the use of steady states as the basis for ambient's unique kind of 'ignoresting' music. ${ }^{28}$

This exemplar was reinforced on the subsequent albums in the 'Ambient' series. Somewhat less so on Eno's collaboration with Harold Budd, Ambient 2: The Plateaux of Mirror (1980), which functioned primarily as a vehicle for Budd's noodling piano improvisations within reticent environments (another kind of 'discreet music'?) created by Eno. Some tracks come close

27 Simon Cummings, "Altered (steady) states", 5:4, accessed May 1, 2019, http://5against4. com/2017/10/03/altered-steady-states-kenneth-kirschner-september-27-2016november-17-2016markus-reuter-falling-for-ascension-formuls-entryiseasierthantheexit_exit/

28 While Eno has not directly referred to his compositional systems for ambient music as 'steady states', he has alluded to the idea when describing the attractiveness of slow movements in the music of Haydn and Mozart, which: "didn't produce emotional surprises, [but rather] presented an emotional situation that held steady for quite a long time. In other words, a 'steady-state' kind of music" (Eric Tamm, Op. cit., 35). 
to the action of a steady state, 'First Light' being one of the best examples, largely comprised of an essentially unchanging (save for registral alterations) undulating arpeggio over which melodic ideas are placed, redolent of Cluster \& Eno. However, across the album there is a more overt sense of linear direction and musical intent, such that very little could be described as 'ignorable'. The album is not, therefore, a convincing representation of Eno's 'ignoresting' dichotomy.

The other two albums in the series are a much more direct and meaningful extension of this fundamental concept of ambient. Ambient 3: Day of Radiance (1980), composed by US instrumentalist Laraaji and produced by Eno, utilises steady states throughout. The three sections of "The Dance"are defined by a behaviour in which rapid, regular dulcimer strikes create a generalised, densely arpeggiated, static harmonic field within which, in the latter two parts especially, small discrete ideas - perceived within subtly shifting pitch emphases - can occasionally be perceived. (While "The Dance" bears something of a resemblance to minimalism, the lack of any clear sense of an ongoing, developing process makes this a merely superficial similarity.) The two 'Meditations' with which Day of Radiance concludes greatly reduce the pace and impact of Laraaji's dulcimer. Their steady states consist of a similar - if somewhat busier - soundworld to that of Music for Airports, with multiple floating strands of dulcimer music intermingling freely in a harmonically fixed environment. "Meditation \#2" sounds more hands-on and coordinated, pivoting around a dramatic - and surely deliberate - burst of overlapping runs and arpeggios two-thirds through, while "Meditation \#1" is much more plausibly an act of passive creation with minimal interventions being made to adjust timbre, density and dynamic.

Eno returned to the creative helm on Ambient 4: On Land (1982). Steady states are again the basis for much of the music, primarily articulated such that the long-term elements are drone-based, deep fundamental tones that underpin almost all of the album's eight tracks. Over these, various transitory ideas appear - strains of melody, gently abrasive noise elements, and forms 
of pseudo-animal, bird or insect sounds - the activity of which is generally meandering and unpredictable. Taken together, the music becomes a kind of subdued equivalent of Tangerine Dream's kosmische musik, exploring (as its title suggests) planet-based landscapes instead of intergalactic starscapes.

Beyond this, On Land is a clear continuation of the thinking that led to Music for Airports, though with several key developments. Where the earlier album was conceived by Eno as "an atmosphere, or a surrounding influence: a tint", On Land is a vivid attempt to expand this into a collection of immersive worlds which the listener is invited to enter and inhabit. This was no merely figurative kind of immersion: in the liner notes to On Land Eno went so far as to devise an "ambient speaker system", enclosing the listener within three speakers (front left/right plus centre rear) thereby enabling his description of the music to become actualised: "I regard this music as environmental: to be experienced from the inside". ${ }^{29}$ An integral part of this experience is Eno's shifting away from his hitherto elusive approach to sound and timbre in favour of sounds directly evoking real-life creatures (though remaining abstract and unidentifiable).

As far as its use of steady states is concerned, the long-term dimension is harmonically simplified in On Land. It shifts away from the richer, triadbased harmonic palette of Music for Airports towards single fundamental drones, the possible harmony of which is only implied through the presence of consonant pitches (which in this more vague context could not really be described as 'diatonic') used in the superimposed melodic elements. Aside from this, though, in all key respects Eno's use of steady states in On Land functions in exactly the same way as previously, providing a balance of longterm, 'ignorable' stasis and short-term, 'interesting' detail and variation.

The potential of steady states to be a compelling means to the creation of ambient music over extended durations can be heard in other works created

29 Brian Eno, "An Ambient Speaker System", in liner notes to Ambient 4: On Land (Editions EG, EGED 20). 
around the same time as the Ambient series. Steve Hillage and Miquette Giraudy's Rainbow Dome Musick (1979) uses a steady state in its 23-minute first half, "Garden of Paradise", arranged via a coruscating background harmonic field over which occasional bell strikes, assorted chords and unobtrusive improvised guitar ideas play out.

The 24-minute title track of Robert Rich's Sünyatā (1982) is structured as a meditative steady state in which - book-ended by a prologue and epilogue of quietly croaking frogs - drifting pitches lightly impinge upon, but in no way threaten, an unwavering $\mathrm{A}^{\mathrm{b}}$ drone. The timbre of the sounds suggests wooden flutes and the human voice, but the reverb with which they are drenched, together with their extremely slow movement, keeps identification out of reach.

All three parts of Steve Roach's 1984 album Structures from Silence involve steady states. The latter two, "Quiet Friend" and the title track, set up unchanging behaviours that provide interest through a slight unpredictability in the order (but not the nature) of their chord progressions. The opening track, "Reflections in Suspension", is similar but its steady state features an additional underlying texture of constant glinting arpeggiations that continues throughout its 16-minute duration. Change is introduced via a somewhat arbitrary, slow-moving bassline - which, while it causes no alteration in the arpeggiations, shifts the implied nature of their harmony - and a separate layer of drifting synth chords, both of which sound passive, subject to whim rather than an effort to direct the music.

At the opposite end of duration, Bill Nelson's Simplex (1990) comprises a collection of tracks lasting between one and three minutes, each featuring a steady state to create a contemplative sequence of miniature vignettes. Due to their brevity, the distinction between long- and short-term activity in this context is essentially moot.

But by far one of the most compelling, large-scale demonstrations of the use of steady states to create 'ignoresting' ambient is the 1994 album Selected Ambient Works Volume II by Aphex Twin, the moniker of UK musician Richard 
D. James. At the time, the title may have seemed misleading; James' Selected Ambient Works 85-92, released the previous year, had borne little resemblance to ambient, instead exploring examples of what would lead to the house- and techno-fuelled generic offshoots from ambient. ${ }^{30}$ By contrast, Selected Ambient Works Volume II constitutes an almost wholesale embracing of the steady state model as exemplified by Eno. Its 24 untitled parts, together spanning over two and a half hours, are simple structures built upon small, cycling motifs - usually in the form of short arpeggiations or chord sequences - that are prolonged to form long-term stases, some (echoing parts of Another Green World) including relatively gentle beats. Over and around these stases, in the same way as previously discussed, assorted transient elements - in almost all cases, essentially sonically unidentifiable - organically and unpredictably emerge, drift and dissolve.

The steady state: nature and implications

Though it has been already stated, and also implied in the examples explored above, it is worth reiterating at this point that a musical steady state, by definition, consists solely of the kind of polarised long- and short-term behavioural paradigm previously described. In the light of this definition, two important points should be clarified. First, a steady state is not synonymous with an algorithm. While it would hardly be difficult to codify a steady state as an algorithm - indeed, they lend themselves well to generative and computational creative techniques - they can be both descriptive and prescriptive. As I have illustrated, they can be employed in intuitive, handson, improvisational contexts such as those explored in the kosmische musik of Tangerine Dream, Another Green World or Rainbow Dome Musick, and also in strict, hands-off, highly formalised situations such as those heard in "Discreet Music", Music for Airports and Structures from Silence. Second, the

30 The notable exception being “i”, a 77-second ambient track akin to the miniatures on Bill Nelson's Simplex. 
definition of a steady state, describing a generalised modus operandi, does not include or imply any notions whatsoever pertaining to specific musical styles or aesthetics. Such considerations are secondary, subjective values that can be applied as desired to the definition of any steady state.

By restating here the true nature of a steady state, particularly its neutrality and adaptability, and asserting its centrality to the conception of ambient as defined by Eno's 'ignoresting' dichotomy, I propose, among other things, to address the question posed by Mark Edward Achtermann:

One question that ambient music seems to ask is whether it is more fully defined as such by its quality or its organization $[\ldots]^{31}$

The 'quality' of not just ambient music but any music is concerned with notions of style and aesthetic, aspects that are personal and idiosyncratic, and therefore sufficiently subjective as to be incompatible with the aim of being definitive, at least in any meaningful way. Indeed, to seek to define ambient via its 'quality' is potentially to risk returning to the fallacy I stated at the outset of this chapter, that ambient music is best or most appropriately defined along the lines of being "slow, quiet, relaxing and beautiful". As Tony Marcus has noted:

The word 'ambient' comes from the Latin and means 'going about' - from 'iens' going, and 'ambi', about. Which doesn't say 'peaceful' or 'beautiful' or 'relaxing'. It just says 'going about'. Which suggests what? Present? In motion? And sort of 'just there' like a gas or perfume, molecules that diffuse in the air? ${ }^{32}$

31 Mark Edward Achtermann, "Yes, but is it music? Brian Eno and the definition of ambient music," in Brian Eno: Oblique Music, eds. Sean Albiez, David Pattie, (London: Bloomsbury, 2016), 102. Achtermann's italics.

32 Tony Marcus, “The 20 greatest ambient albums ever made," Fact, July 19, 2011, https://www. factmag.com/2011/07/19/20-best-ambient/. 
It is therefore my contention that ambient is best defined by its organisation. The steady state, encapsulating a behavioural mode of operation devoid of aesthetic considerations, and thereby stylistically neutral, is therefore best placed to be regarded as the sine qua non, and perhaps the defining aspect, of the 'ignoresting' compositional methodology of ambient. As such, it can be regarded as the quiddity of ambient, objectively transcending any and all boundaries of personal creative whim. Subjective aspects, such as those implied in 'quality', constitute merely the haecceity of ambient, the collection of qualitative identifiers pertaining to a specific composition by an individual composer.

Misplaced focus on haecceity rather than quiddity inevitably causes the potentiality of ambient - in terms of both the way it can be explored and articulated, and the breadth and range of its influence - to be misunderstood and very greatly underestimated. For, while one could identify a number of shared characteristics among many of the examples of ambient discussed above - such as the use of conventionally tonal harmonic palettes - as previously shown it is not these that ultimately unites them, but their fundamental behavioural framework.

In this regard, it is interesting to note the palpable aesthetic shift heard on Eno's On Land, in which many of the tracks actively avoid aspiring to superficial notions of relaxation or 'attractiveness' in favour of brooding, ominous, even oppressive atmospheres. In conjunction with the role of immersion suggested when listening to that album, this only makes the landscapes of On Land all the more disquieting and unsettling. This is echoed on Aphex Twin's Selected Ambient Works Volume II, which overall is at some remove from conventions of tonality and peacefulness. Several tracks are highly abstract (1.10 "Tree", 1.12 "White Blur 1")33 and/or incorporate noise (2.4 "Grey Stripe", 2.9 "Spots", 2.10 "Tassels") and many actively avoid harmonic certainty or clarity. Instead

33 While all but one of them are untitled, the 24 tracks on Selected Ambient Works Volume II are known colloquially by terms derived from images found in the album's accompanying artwork. 
the emphasis is entirely on behaviour, both in terms of the way individual tracks prolong their uniquely-articulated behaviours over time as well as the wider meta-prolongation of the album's overall steady state modus operandi. Occasions when the music overtly projects a gentle, soothing demeanour - the best example being 2.8 "Lichen"- are thus merely coincidental instances within a broader, aesthetically pluralistic and peripatetic exploration of ambient.

That ambient should be regarded as entirely distinct from superficial and qualitative aspects is not surprising. Early hearings of Music for Airports had, if anything, the opposite effect of the relaxation with which that album in particular, and ambient in general, tends to be associated. Victor Szabo recounts how,

[...] various listener accounts give reason to question the extent to which Eno's album ameliorates anxiety, and proffers a sense of security, within real airports. When Eno's music was first installed at New York's LaGuardia Airport in 1980, some airport workers and travellers reportedly complained that the music induced unease. As one remarked, 'It sounds like funeral music'. [...] And if that weren't enough, in 1984 the music sparked protest from employees at Berlin's Tegel Airport who were annoyed by the acoustic 'interference'. ${ }^{34}$

Furthermore, Szabo suggests the responsibility for ambient not functioning in a soothing way is at least in part a direct consequence of the unique longand short-term behavioural flux fundamental to the steady state.

While these tracks promote an overarching sense of stability by constraining the parameters of global, or long-term change, a number of local, or short-term variabilities keep the music from resting on certain ground. Although the sounds used in each recording remain

34 Victor Szabo, "Unsettling Brian Eno's Music for Airports," Twentieth-Century Music 14, No. 2 (2017): 311. 
within a single modal pitch collection, the irregular, seemingly unmotivated oscillations between major and minor sonorities within each collection lend the music an emotional mercuriality. And although the non-periodicity of repeated sonic iterations relieves listeners of expecting their metric placement, these sound events also overlap indiscriminately, and dissipate into indefinitely long echoes, creating a bounty of micro-variations in timing and timbre. Within the tracks' overall stable texture, such irregularities generate just enough light turbulence to keep those on board with the music from nodding off. Though seemingly weightless and placid at a distance, the music remains astir and amiss, possibly fostering an uncanny sense that the music's stability is a ruse. ${ }^{35}$

\section{Meta-ambient}

Since the quiddity of ambient, defined in the steady state, is concerned solely with behaviour and contains no information regarding style, aesthetic or quality, this has implications on the extent of music that can be regarded as being, at least to some degree, 'ambient'. Indeed, defined in this way the reality of ambient extends to a plethora of diverse aesthetics and contexts, including music not necessarily described or intended by their composers as 'ambient' - what we might term 'meta-ambient'.

A case in point can be found as far back as 1962, in US experimental electronic composer Raymond Scott's three-volume series of albums Soothing Sounds for Baby. ${ }^{36}$ All three volumes employ steady states in every track, a foundation of repeating patterns and arpeggios over which melodies are placed. Utilising early computer technology, the range of timbres employed by Scott is often harsh, sibilant and piercing, and in some cases (most obviously

35 Ibid.

36 The albums are intended to accompany the first year-and-a-half of the baby's life, one volume for each six-month period. 
"Toy Typewriter" and "Tin Soldier") highly percussive. The music's timbral nature, together with the equally subjective responses to Eno's steady states recounted by Szabo, suggests that Scott's title for this series may perhaps have been somewhat optimistic, yet the music can nonetheless be regarded objectively as an early instance of meta-ambient music.

Further examples of meta-ambient abound in more recent electronic music. Each hour-long part in the so-called "Trilogy in Three Parts" by The Hafler Trio $^{37}$ is founded upon a deep, seemingly eternal, fundamental note C, the timbre of which is elusive but evokes both cello and double bass. I have previously noted how,

$[t]$ his fundamental is powerfully omnipresent; everything else takes place above it, sometimes below it, always in relation to it. The music comes across as a luxuriant paean to the harmonic series - or, rather [...], a celebration of all the explicit and implicit harmonic richness contained within that single deep fundamental note. ${ }^{38}$

Against this quasi-static drone, each part in the trilogy introduces episodes focusing on different pitch-class groups: Cleave: 9 Great Openings (2002) uses the pitches closest to $\mathrm{C}$ in the harmonic series (C, D, E, F $F^{\#}, \mathrm{G}, \mathrm{A}$ and $\mathrm{B}^{\mathrm{b}}$ ); No Man Put Asunder: 7 Fruitful And Seamless Unions (2003) does the opposite, using more unrelated, relatively dissonant pitches $\left(\mathrm{D}^{\mathrm{b}}, \mathrm{E}^{\mathrm{b}}, \mathrm{F}, \mathrm{A}^{\mathrm{b}}\right.$ and $\left.\mathrm{B}\right)$; and No More Trwain, Of One Flesh: 11 Unequivocal Obsecrations (2003) is the simplest, using only the notes $\mathrm{F}$ and $\mathrm{G}$, producing the most 'pure' intervallic relationships with the fundamental. Each individual part of the trilogy, and the trilogy as a whole, thereby comprise the prolongation and metaprolongation of a steady state behaviour as well as a harmonic prolongation

37 a.k.a UK experimentalist Andrew M. McKenzie.

38 Simon Cummings, "Contemporary Epics: The Hafler Trio - Trilogy in Three Parts," 5:4, accessed 14 May, 2019, http://5against4.com/2011/10/19/contemporary-epics-the-hafler-trio-trilogy-in-threeparts/. 
(in the Schenkerian sense), the pitches introduced in the episodes acting as temporary dissonances ultimately prolonging the underlying 'tonic' C. ${ }^{39}$

Many of the experimental electronic works by US composer Kenneth Kirschner are meta-ambient in nature, most especially the series of indeterminate pieces Kirschner created in 2004 and 2005. The pieces are generative, produced in real-time within a web browser using the Adobe Flash software. Various banks of samples - containing a mix of sounds and silences - arranged in layers, are selected from at random according to very basic rules. In a similar way to the hands-off composition process of Music for Airports, Kirschner's involvement in the indeterminate works extends no further than devising the range of sounds and the rate at which each layer is introduced; once set in motion, they continue until a stop button is pressed by the listener. The presence of silences in the sample banks is crucial to preserve clarity in the texture as it grows in complexity, as additional layers are introduced over time. One of the most impressive of these indeterminate works - and, in its use of non-rhythmic, largely unidentifiable sounds, most similar to the examples of ambient previously discussed - is January 15, 2005, ${ }^{40}$ consisting of "fourteen lengthy fragments of abstract electronics layered five times to produce an intense, heavy, seamless acoustic soundscape that keeps reinventing itself over very long periods of time". ${ }^{41}$ Steady states, with varying degrees of strictness and perceptibility, have continued to be a key part of Kirschner's musical language in both his indeterminate and fixed compositions.

39 This sense of both harmonic and behavioural (meta-)prolongation is reinforced by the fact that the first two parts of the trilogy do not 'end' as such but are abruptly cut off, implying that they are only stopping due to the durational limitations of the CD medium and that the next part should in fact continue seamlessly.

40 January 15, 2005 can be played at the following URL: http://kennethkirschner. com/011505/011505.html.

41 Simon Cummings, "Determined/Indeterminate: An Exploration of the Music of Kenneth Kirschner," in Imperfect Forms: The Music of Kenneth Kirschner, ed. Tobias Fischer (Tokafi, 2014), 19. http://www.tokafi.com/static/tokafi/img/Kenneth\%20Kirschner\%20Imperfect\%20Forms.pdf. 
As might be inferred from the aforementioned antecedents in minimalism, examples of meta-ambient can readily be found in the world of instrumental music. US composer Steve Peters' work The Webster Cycles (1981) dates from only three years after Music for Airports, and operates in a directly comparable way. Composed for one to five wind instruments, Peters describes the piece as a "found score", ${ }^{42}$ comprising all the words in the Webster dictionary containing only the letters $A$ to $G$, arranged in alphabetical order. In a manner similar to Riley's In $C$, these words are performed as melodic phrases by each player independently (each word to be played within the limits of a single breath), moving from word to word at their own pace. In performance, a steady state is quickly established through the unchanging behaviour of the players steadily articulating the series of words, with the music's surface continually varying according to the harmonic friction and sympathetic resonances arising from its limited but ever-changing pitch content.

The long-form works of German composer Jakob Ullmann, such as PRAHA: celetná - karlova - maiselova for voice and ensemble (2004-7) and Müntzers stern for solo bassoon (2014-15), draw on steady states that could be characterised as harnessing the passive, pseudo-silent ambience of the performance environment as the long-term aspect (sometimes with the addition of drones or otherwise sustained pitches). Smaller-scale interest and change comes in the form of small, active sounds that are delicately placed or projected into this ambience. Oliver Thurley describes how in Ullmann's music, due largely to its quietness, the liminality of the steady state takes on an extreme fragility, heightening listener's perceptions,

[...] quietness draws the listener's attention into the music, revealing new dimensions, yet the music simultaneously attempts to evade focus through its quietness and static structure. [...] The music never makes any sort of expressive gesture; it remains brittle throughout,

42 Steve Peters, The Webster Cycles (self-published, 1981). 
presenting the listener with a constant and unrelenting soundscape that balances precariously at the brink of perception: a fragile listening experience. [...] For the listener, the music presents itself as sound in constant flux, which although constantly moving, has no clear telos and never goes anywhere. This stasis too is a function of the fragility in Ullmann's work as one's ability to listen to the work is made precarious [...]; the structural stasis of the pieces accentuates the listener's sensitivity to the most subtle changes in the texture. ${ }^{43}$

That such music can be regarded as meta-ambient is reinforced by Ullmann's indications in the liner notes of his albums, which are essentially identical to Eno's conception of ambient listening:

To achieve the original sound quality of this live recording it is suggested to listen to this $\mathrm{CD}$ at the lowest possible volume. ${ }^{44}$ We would like to point out that this piece is extremely quiet. Please choose the volume setting of your sound system so as to just barely mask the ambient sounds of the room. ${ }^{45}$

Aesthetically similar steady states can be found in works by composers associated with the German-based Wandelweiser collective. Structured upon modes of behaviour that tend to remain consistent over extended periods of time (sometimes many hours), the majority of these compositions, like those of Ullmann, incorporate silence as an integral element in the long-term aspect of their respective steady states. ${ }^{46}$

43 Oliver Thurley, "Disappearing Sounds: Fragility in the Music of Jakob Ullmann," Tempo 69, No. 274 (2015): 18-19.

44 Jakob Ullmann, liner notes from A catalogue of sounds (ed. RZ 1017, 2005).

45 Jakob Ullmann, liner notes from voice, books and FIRE 3 (ed. RZ 2005, 2008).

46 For a detailed early account of the history and outlook of Wandelweiser, see Michael Pisaro, "Wandelweiser," erstwords, accessed 14 May, 2019, http://erstwords.blogspot.com/2009/09/ wandelweiser.html. 
The slow rates of change that typified the earlier electronic work by French composer Éliane Radigue have in recent years found a parallel in her instrumental music. Radigue's ongoing Occam Ocean project involves slowly-shifting pitch environments either rooted in fundamental drones or sustained chords that establish long-term behavioural stasis - a generally flat dynamic contour, just one or two modes of articulation - where, again, short-term variation is heard and felt in the way pitches collide against one another, leading to "complex overtones and undertones [forming] ephemeral constellations of musical relationships" ${ }^{47}$

British composer Rebecca Saunders has composed numerous ensemble pieces she describes as 'collages', in which various numbers of 'sound surfaces' are superimposed upon each other. These works, such as murmurs (2009), directly employ steady states. Both the nature of each player's material and the way it is are articulated are specific yet vague, with "[a]11 sounds, where possible, surfacing out of, and disappearing into, silence". ${ }^{48}$ These individual materials are superimposed to form a vague, nebulous murmuration in which "[e]ach line is fragile and imperfect, and is thread through the collage of changing density". ${ }^{49}$ Performed at a level of extreme quietness, murmurs quickly displays a meta-ambient behavioural stasis formed from these quasi-arbitrarily juxtaposed 'sound surfaces' that "continually pulls one's focus between attention on solos, pairs and larger groupings, at the same time causing one to question whether sonic events are, in fact, connected" ${ }^{50}$ Furthermore, the importance of ambience is directly referenced in the score, Saunders insisting that a "dry acoustic is to be completely avoided!" 51

47 Luke Nickel, “Occam Notions: Collaboration and the Performer's Perspective in Éliane Radigue's Occam Ocean," Tempo 70, No. 275 (2015): 22.

48 Rebecca Saunders, Introductory notes to murmurs (Peters Edition, 2009).

49 Ibid.

50 Simon Cummings, “CBSO Centre, Birmingham: BCMG - Murmurs," 5:4, accessed 16 May 2019, http://5against4.com/2019/03/24/cbso-centre-birmingham-bcmg-murmurs/.

51 Rebecca Saunders, Ibid. 
Within the scope of this chapter it is of course not necessary (or possible) to continue with an exhaustive summary of music that might be regarded as meta-ambient. It is left to the reader to consider and question other examples that might fall within the sphere of ambient as defined by the neutral, objective behaviour of steady states. For example, if behaviour is the guiding principle rather than subjective or stylistic elements, does ambient need to be quiet? If the 'ignorability' of ambient implies an act of withdrawing (voluntarily) from the music due to a paucity of engaging elements, might 'repulsability' be its polar equivalent, an act of withdrawing (involuntarily?) from the music due to an overload of engaging elements? And if so, could certain types of Noise music be considered meta-ambient? Apropos the music of Phill Niblock, which has pushed the soundworld of Éliane Radigue to its limits, prompting Robert Ashley to describe works like Disseminate as "hardcore drone". ${ }^{2}$ Apropos the music of Zbigniew Karkowski, whose music can in part be regarded as an opposite of sorts to Jakob Ullmann: where Ullmann delicately encroaches into a silent space, Karkowski subtly encroaches into a saturated space. ${ }^{53}$ As an inversion of the microsound-focused subgenre of ambient named by composer Steve Roden as lowercase, ${ }^{54}$ might we conceive of these extreme musics as UPPERCASE?

\section{Conclusion}

I began this chapter looking up at the stars, and by way of drawing to a conclusion, I now return to them - or, at least, to the impulse that causes us to look up. From its inception, through the vagaries of New Age and the voyages of kosmische musik to the atmospheres and tints of Eno and beyond, ambient music has always found itself attributed with extra-musical

52 Robert Ashley, liner notes to Pbill Niblock - Disseminate (mode 131, 2004).

53 Furthermore, Karkowski's UEXKULL (1991) draws strong comparisons to The Hafler Trio's 'Trilogy in Three Parts'.

54 See Steve Roden, “On Lowercase Affinities and Forms of Paper," Line, accessed 14 May, 2019, http://www.lineimprint.com/wp-content/uploads/2011/10/line_053_essay.pdf. 
connotations pertaining to that which we might loosely call 'beyond'. The proto-ambient of Tony Scott and Paul Horn sought directly to channel their respective faith-based meditative methodologies. This extended to the titles of the tracks - e.g. "A Quivering Leaf, Ask The Winds", "Enlightenment" (Scott), "Mantra I / Meditation", "Vibrations" (Horn) - seeking to evoke and stimulate mystical or spiritual thought and provide a sonic environment within which contemplation could take place. Tangerine Dream sought to tap into something indefinable yet awe-inspiring by allowing their - and our - imaginations to run riot through hypothetical soundscapes of the universe. Eno too sought both to colour existing environments and to create entirely new sonic habitats for the listener to occupy.

The merits (or otherwise) and implications of such extra-musical perceptions, regardless of whether they are applied by their composers or listeners, are beyond the scope of this chapter. Yet the nature of the steady state may well be pivotal to the way in which such perceptions become manifested so readily in ambient (and, potentially, meta-ambient). The role of randomness - whether actual or merely perceived - in steady states is analogous to John Cage's turning to chance procedures in the 1950s, eschewing rigorous procedural methods $s^{55}$ in favour of a means to overcome higher-level decision-making through an obviation or even sublimation of the self. Furthermore, the endless, potentially timeless, nature of steady states - by definition capable of continuing their 'ignoresting' behaviours forever, transcending notions of beginning or end - indicates a polar opposite to the finitude and decay of the world, and perhaps thereby goes some way to satisfying human inclinations to eternity and the beyond. ${ }^{56}$

That the musical results of steady states can be subjectively perceived as articulating a 'narrative' with which we can emotionally (and spiritually)

55 Methods best exemplified at the time by the integral serialism of Pierre Boulez.

56 That being said, steady states can, of course, be utilised as the vehicle for a musical process of decay. A well-known example of this can be heard in William Basinski's The Disintegration Loops (2002-3). 
engage is beyond question. In relation to the aforementioned indeterminate works of Kenneth Kirschner, I have previously explored how these pieces,

[...] when heard over extended periods of time [...] are indeed narratively null, exhibiting a long-term equilibrium. But reducing one's aural scope - an entirely legitimate thing to do, as the durational and structural aspects of these pieces are undefined and aleatoric, respectively - the music passes over peaks of intensity and through valleys of repose, a process that invites connections to be made between what has passed, what is happening now and what one expects may happen soon. Moreover, the peaks occasionally expand into powerful lengthy plateaux, becoming transfixed, ecstatic even. ${ }^{57}$

Without directly invoking spiritual connotations, Jakob Ullmann's use of steady states nonetheless indirectly functions to establish a uniquely heightened environment that could be said to draw distinct perceptional parallels. Thurley writes of how Ullmann's works "blur the listener's ability to identify what is being heard in a densely fused homogeneous stasis", a process exacerbated by keeping the performers hidden from the audience. This has led to what Thurley calls "a theatre of the invisible", producing "the unnerving effect of an eternal, omnipresent acousmêtre". ${ }^{58}$ Indeed, to return to Victor Szabo's remarks about the disquieted early public responses to Eno's Music for Airports, it is conceivable that the disturbing "uncanny sense" engendered by the music's use of steady states is perhaps akin to the profound emotional response that German theologian Rudolf Otto conceived as the numinous. ${ }^{59}$

57 Simon Cummings, "Determined/Indeterminate: An Exploration of the Music of Kenneth Kirschner," in Imperfect Forms: The Music of Kenneth Kirschner, ed. Tobias Fischer (Tokafi, 2014), 20.

58 Oliver Thurley, Op. Cit., 20. The term 'acousmêtre' - a portmanteau of 'acousmatic' and 'être' - was coined by Michel Chion to describe a voice that "has not yet been visualized [...] a special kind of being, a kind of talking and acting shadow [...] whom you have never seen". Michel Chion, The Voice in Cinema (New York: Columbia University Press, 1999), 21.

59 Rudolf Otto, The Idea of the Holy, trans. John W. Harvey (Oxford University Press, 1923), 7. 
In this chapter I have sought to present the steady state as the essential, objective, universal component - the quiddity - of ambient music, as encapsulated in Brian Eno's 'ignoresting' dichotomy. In contradistinction to the assumption that ambient is best defined by subjective, superficial qualities, I have shown how this is fallacious, at odds with the non-specific openness of Eno's own definition and practice of ambient, and have argued that it is most appropriately defined by behaviour. As both a compositional approach and listening experience, the 'ignoresting' dichotomy is subtle. Paul Morley has characterised ambient as,

\section{[...] the missing link between dubious muzak and artful minimalism, between the whispering of space and the whispering in space, between form and formlessness, between content and contentment". ${ }^{60}$}

Such descriptions emphasise the essential duality of ambient, positioned at a crucial, liminal point between opposite poles with regard to intention, perception and engagement. But that is where its definition, as such, ends; the dichotomy accounts for how ambient should behave, what it should be, but neither states nor suggests anything about what it should be like.

As the quiddity of ambient, the steady state likewise says nothing about style, aesthetic or quality, instead describing only the music's underlying organisation. This directly engages with the behavioural paradigm established by Eno in "Discreet Music", Music for Airports and On Land, in which self-contained, unchanging ideas repeat in proximity to one another in an unpredictable way. This results in non-teleological music in which this fundamental, unchanging behaviour is clarified through meta-prolongation, characterised by a polarised juxtaposition of small-scale, short-term change and large-scale, long-term stasis. It is my assertion that the modus operandi

60 Paul Morley, Words and Music: A History of Pop in the Shape of a City (London: Bloomsbury, 2003), 20. 
harnessed in the steady state is the most fundamental and compelling means by which to manifest Eno's 'ignoresting' dichotomy. The inevitable tension between its poles of ephemeral change and eternal immobility result in what David Toop has lyrically described as,

[...] drifting or simply existing in stasis rather than developing in any dramatic fashion. Structure emerges slowly, minimally or apparently not at all, encouraging states of reverie and receptivity in the listener that suggest (on the good side of boredom) a very positive rootlessness. ${ }^{61}$

The tension in steady states, mirroring the nature and action of the universe and capable of being perceived and interpreted from both intra- and extramusical perspectives, is thus a palpable and vivid way to elicit the ambivalent responses of engagement and disinterest in the listener that were, are and always will be the quiddity of ambient music.

61 David Toop, Ocean of Sound (London: Serpent's Tail, 2001), ii. 